\title{
COMMENT
}

DOI: $10.1057 /$ s41599-018-0159-8

\section{Turning psychology into policy: a case of square pegs and round holes?}

\author{
Carl Walker ${ }^{1}$, Ewen Speed ${ }^{2} \&$ Danny Taggart ${ }^{2}$
}

\begin{abstract}
This paper problematizes the ways in which the policy process is conceived in published psychological research. It argues that these conceptions of the policy process fail to adequately reflect the real-world dynamism and complexity of the processes and practices of social policy-making and implementation. In this context, psychological evidence needs to be seen as one type of evidence (amongst many others). In turn this requires researchers to take account of broader political processes that favour certain types of knowledge and disparage others. Rather than be regarded as objective and scientific, policy in this characterisation is regarded as a motivated form of politics. This multi-layered, multi-level hybrid structure is not immediately amenable to the well-intentioned interventions of psychologists. While the tendency of many psychologists is to overestimate the impact that we can have upon policy formation and implementation, there are examples where psychological theory and research has fed directly into UK policy developments in recent years. This paper draws on the recent Improving Access to Psychological Therapies (IAPT) initiative and the work of personality researcher Adam Perkins on the UK's social security system to ask whether psychology has a sufficiently elaborated sense of its own evidence base to legitimately seek to influence key national areas of public policy. The article cautions against dramatic changes to policy predicated upon any one reading of the variegated and, at times, contradictory psychological evidence base. It concludes that, in order to meaningfully contribute to the policy development process in a way which increases equality and social justice, psychologists need to be more strategic in thinking about how their research is likely to be represented and misrepresented in any particular context. Finally some possible directions for psychologists to take for a more meaningful relationship with policy are suggested.
\end{abstract}

\footnotetext{
${ }^{1}$ Applied Social Science, University of Brighton, Brighton, UK. ${ }^{2}$ School of Health and Social Care, University of Essex, Essex, UK. Correspondence and requests for materials should be addressed to C.W. (email: C.J.Walker@brighton.ac.uk)
} 


\section{Representations of policy in psychological research}

- he original 'scientist of happiness' Jeremy Bentham is commonly regarded as the individual who, more than any other, brought the phenomenon of 'evidence based policy making' into being. The sociologist Will Davies states that, "Whenever a policy is evaluated for its measurable outcomes, or assessed for its efficiency using cost benefit analysis, Bentham's influence is present." (2015). It is important to bear this influence in mind therefore, when almost 250 years later, the discipline of psychology (via the 'measurement' of human experience), is aiming to stake a claim for a central role at the heart of the UK policy agenda.

At issue here is the way in which much academic research, and psychological research in particular, conceives of, and engages with, policy processes. Typically, this involves a naïve reading of policy context (which happens somewhere else, away from the disciplinary context of the research) which is painted as unidimensional and something that can be relatively easily influenced, with no need to address questions of complexity, or other disciplinary and professional boundaries. The assumption tends to be that policy should come to their research, rather than thinking (concretely) about how they, themselves, not some ghostly, ill-defined (and supplicant) policy actor, might make their research policy relevant for them. This fundamental lack of connection with existing policy processes, demonstrates as Cairney (2016) has argued, that researchers are engaging with the policy process that they wish existed rather than the processes which actually exists. The policy processes which do exist are predicated upon internal and external hierarchies of evidence, and processes and practices of influence, patronage and lobbying which are far removed from two throw away lines in the conclusion of an academic paper stating that the preceding research has policy relevance and impelling policy makers to sit up and take notice (whomsoever those policymakers might be-they are seldom if ever identified). This is to say nothing of the wider ideologically framed political and discursive formations that influence what it is possible to imagine in a policy arena at any one place or time.

To illustrate this complexity, and the attendant constraints upon psychological research impacting upon the policy process, we take an example where psychological research has been adopted in a highly selective way; the development of psychological treatments for common mental health issues. Our argument is that, in order to meaningfully contribute to the policy development process in a way which increases equality and social justice, psychologists need to be more strategic in thinking about how their research is likely to be represented and misrepresented in any particular context. This requires a political awareness and engagement that historically psychologists, in the interests of scientific distance, have been wary of.

In terms of the political context, the ghost of utilitarianism looms large. A rigid hierarchy of evidence, primarily predicated upon questions of economic value (broadly construed), dominates the field (Cairney, 2016). Even then, even if the paper has the highest standard of evidence, this does not necessarily guarantee that this evidence will be picked up by policy makers or politicians. If there is no political case for the policy, there will be little chance of the evidence being implemented in a policy context. The point is that demonstrating economic value is not enough, there is also a clear and present need to demonstrate the political expediency of any proposed policy, (regardless of the evidence). It is in this context that we see policy-based evidence, rather than evidence based policy (see Cairney, 2018), where policymakers may make very selective use of the evidence in a way that supports their view and denigrates another view. Consider the implications of this dynamic process for an academic paper which claims policy relevance, but does not direct this to a when or a where. In this context the academic research could, it is argued, be up for grabs, ready and able to deployed in any number of ways, that may, or may not contradict the intention of the original research.

Earlier we argued that this insistence, on the part of psychologists, reflects a naïve reading of the policy context. Furthermore, this failure to engage with the dynamic complexity of policy practices and processes runs the risk of reifying this mischaracterisation. Such is the vagaries and iniquities of the policy process that there is a need to acknowledge and address these vagaries if research is to have a meaningful and significant impact. There is a compelling evidence that outlines the way that policies are often driven by ideology and biases rather than evidence (Fishbeyn, 2015, Prinja, 2010). Cleary then, there is a danger that psychological research, which argued position $\mathrm{X}$, can and will be taken up by politicians or policy makers and deployed in a way which argues position Y. And, if the characterisation of the policy process envisaged by researchers is the reified mischaracterisation we outline above, the danger of this misrepresentation of the tone and tenor of academic research becomes far more likely to occur, as policy makers and politicians assert their dominance (over the evidence makers, i.e., academic researchers) in the policy arena.

All of this talk relates to issues in and around the policy process, that is to say, the practice of social policy, how it works. But there is also a need to address issues of context, those social, political, economic and cultural spheres where the practice of social policy is enacted. There is a clear need to conceive of the relation between these different spheres in terms of the influence and impact that psychology might have on policy process and practice, but also, in terms of the influence and impact that policy might have on psychology. Failure to consider this 'to-and fro', or 'ebb and flow' would run as much of a risk of policymakers reifying psychological research as the obverse process we set out here.

This requires psychologists, as a professional group, to give serious discussion and debate to what they are doing in a broader social, political economic and cultural context. It requires psychologists to raise questions about how they should (or should not) contribute to policy. Moreover, questions about the reliability of the psychological evidence base, as well as a tendency to celebrate the statistical flukes left standing after researchers have cast around to find publishable positive results (Rhodes, 2015) has left psychologists Farsides and Sparks (2015) to suggest that 'psychology is liberally sprayed with bullshit' (p368).

\section{IAPT, the welfare trait and 'policy-ready' psychology}

While the tendency of many psychologists is to overestimate the impact that we can have upon policy formation and implementation, there are examples where psychological theory and research has fed directly into UK policy developments in recent years, with some influence. By focusing on a high profile example we can then examine not only if psychology has an impact but more importantly what that impact has been.

The Improving Access to Psychological Therapies (IAPT) initiative is arguably the jewel in the crown of applied psychology's influence on UK mental health policy, with the rest of the world taking note (NYT, 2017). Based on an elegant economic cost-saving calculation (the ghost of Bentham again), by the UKs 'Happiness Tsar' and economist Richard Layard, combined with evidence-based psychological therapies (primarily CBT), one could reasonably ask what's not to like? While we of course can see the value in the opportunity for many thousands of people to 
undertake a course of psychological therapy to alleviate their mental health issues and to bring an important psychosocial dimension into mainstream mental health care, there are unintended and unhelpful consequences of the IAPT agenda that need to be considered.

Firstly, as with many policy initiatives, there is the gap between the political rhetoric and the clinical reality. IAPT has, from the beginning, made ambitious claims about its effectiveness, offering treatment to 900,000 patients annually and achieving a 50\% recovery rate for depression, anxiety and related 'common mental health problems.' (Clark, 2011). It should be borne in mind that this level of treatment was necessitated in order to produce the 'zero net cost' of IAPT at the policy development stage through promising savings in physical health care, numbers of welfare claimants and a reduction in mental health related sick days (Clark, 2011).

Whilst IAPT has lived up to some of these promises, with undoubted successes in treatment effectiveness (recovery figures approaching 50\% for those who complete treatment, NHS Digital, 2017), there is some cause for concern around evidence that the 'IAPT effect' has not been entirely benign. For example, in IAPT monthly data summary for December 2017 NHS data (NHS Digital, 2017), 89,485 new referrals were received with 68,205 referrals entering treatment. Of this number 39,834 completed a course of treatment with 37,238 starting treatment with 'caseness' (the referral has enough symptoms to be regarded as clinical) and $49.9 \%$ of those approaching recovery by the end of treatment. This data means that only $22.25 \%$ of the total referrals were considered to be getting better. That means that in this month over $72 \%$ of referrals coming for help either did not receive any treatment at all, did not receive a full course of treatment or did not get better by IAPT's own metrics.

If we are more conservative and remove those who did not start treatment from our calculation, the situation improves slightly to $27 \%$ of referrals achieving recovery and even if we assume that one referral does not equate to one person, that is still a lot of disappointed, disillusioned and worried people. Given that these dropout figures are roughly comparable with other time points in IAPT's history (McInnes, 2014) this is cause for concern. Add to this the study which found that, for a sample who did achieve recovery using low intensity forms of IAPT, 53\% relapsed within one year (Ali et al., 2017) and we can see that the more carefully we look at the psychological evidence base for IAPT policy the more questions arise.

Given widespread reductions to specialist mental health services, it seems likely that IAPT, a brief, often self-directed form of psychological treatment for mild to moderate mental health issues is being expected to plug the gap left by the reduction in longer term community services. As Watts (2016) points out, in IAPT's own analysis dropout figures are not seen as a criticism of the initiative itself as they are not counted in recovery figures. Furthermore, in trying to bring people into services in order to meet policy-based treatment targets we may inadvertently be creating need in people and then not meeting it, a particularly 'perverse form of care' likely to have a detrimental impact on the mental health of many left behind by the IAPT revolution.

Additional evidence demonstrates that the number of people not recovering through IAPT approved CBT are disproportionately from poorer communities (Delgadillo et al., 2015). In the 2015-2016 IAPT annual report (NHS Digital, 2016), 55\% of referrals in the least deprived $10 \%$ of areas achieved recovery, while in the most deprived $10 \%$ of areas only $35 \%$ achieved recovery. This can be likened to an extension of the inverse care law' whereby not only do people in more disadvantaged communities struggle more to get access to healthcare, when they do it is less effective in helping their mental health. To what extent this is a failing of IAPT per se and how much it reflects the causes of common mental health issues in disadvantaged communities being less psychological and more social (Speed and Taggart, 2012) is beyond the scope of this paper but is also worth considering when assessing psychology's readiness to take an intrapsychic perspective to the exclusion of other models.

From this we can begin to see that laudable claims of treating common mental health issues for hundreds of thousands of people annually involves unintended consequences of alienating many from trusting services and repeating the pattern of further marginalising those already structurally disadvantaged. Indeed, it is our argument that it is the very 'policy ready' nature of IAPT that has precipitated many of these unintended consequences. Its grand, possibly hubristic vision of 'curing' common mental health issues and reducing the economic burden of the 'mentally ill' undoubtedly plays well in a political era that privileges an instrumentalist, Fordist and market-oriented approach to public services, but the scale of the claims needed to provide a 'bottom line' appeal was always likely to demand much and leave many staff and patients behind. This is largely because Benthamite cost-benefit analyses are not a sufficient basis upon which to predicate the policy and practice of mental health care because they ignore the processes and contexts of mental health, out there, in the world.

Another source of 'policy-ready' psychological research comes from the personality researcher Adam Perkins in his work 'The Welfare Trait' (2015). Perkins makes a case for a fundamental restructuring of the UK's social security system based on an assertion that overly generous welfare provision for out-of-work parents results in the proliferation of what he describes as an 'Employment Resistant Personality' profile that leads to welfare claimants having more children and negatively impacting national productivity. Whilst questions have been raised about whether this work is of merit as psychological science, the issue we want to address here is whether psychology has a sufficiently elaborated sense of its own evidence base to seek to influence a key national area of public policy as social security?

To take the Welfare Trait example, even Perkins notes the perverse logic in cutting welfare payments for families with multiple children, thereby depriving already disadvantaged children of resources. On this point there is a consensus of agreement. However, Perkins draws from a 1975 study (Tonge et al. 1975) of 33 Sheffield families to suggest that this perverse logic can be ignored as welfare claimants all "spend their welfare benefits on unnecessary purchases such as electronic gadgets and luxury chocolates, instead of using the money to improve the lives of their children." (Perkins, 2015 p.177). This conclusion seems emotive and polemical rather than being based on any robust evidence. This conclusion on the part of Perkins is clearly not the type of psychological evidence that we want to use to determine the life chances of millions of children.

When we add a competing example of psychological evidence, an analysis which found that levels of referral for maltreatment were causally related to the income variation in low income families in the US (Cancian et al. 2010) with reductions in income leading to an increases in maltreatment cases, we can see that dramatic changes to welfare policy predicated upon any one reading of the variegated and at times contradictory psychological evidence base can be downright dangerous.

\section{Concluding thoughts}

We would like to end by urging caution on psychologists who aim to have a 'policy impact'. Instead, we suggest a level of professional engagement in policy processes, whereby psychological evidence is used to forge alliances with common interest groups, for example, to lobby ministers for particular reforms or new initiatives. So rather than merely referencing policy implications in research 
papers, there is a wider social undertaking to make research evidence available to communities impacted by the social problems under investigation in order to enable them to petition for change.

In some mental health research contexts this is already happening, where alliances have been formed between psychological researchers and mental health service user groups. In the Understanding Psychosis (2014) project there is a clear move towards the dissemination of research findings regarding aetiology, symptomatology and treatment for psychoses and associated mental health issues that largely draws upon preexisting psychological research alongside first person testimonies and activism from people with that diagnosis. Therefore, in this case the research acts as a form of social activism in which evidence is used explicitly in the interests of those it purports to be about, allowing them a very real, present and active voice in talk about their mental health. However, there is a bind that comes with this 'bottom up' approach to influence, and it is one that resonates with the naivety (even futility) of claims regarding the policy relevance of psychological research that we critiqued in this paper. Unless there is a vested interest policy actor working with the psychological researchers, the chance of any research gaining any degree of purchase in the field is at best limited.

The great achievement of the IAPT agenda was the alignment of psychological evidence, the vested interests of the profession of clinical psychology wanting to expand its sphere of influence in an historically medically dominated field with the social democratic, utilitarian ethos of a key policy influencer in Richard Layard. This placed psychology and its practitioners in a position of previously unimaginable influence within mental health service development in the NHS, with the opportunity for future mission creep into other areas. But, to return to Cairney (2018), this was largely because the psychological evidence corresponded to the policy reality (i.e., for IAPT, psychology was able to present policy-based evidence, rather than IAPT being drawn from evidence-based policy). As such, its policy influence had material, resource-based advantages in a way that alignment with the service user movement will not, because, it is much more unlikely that service user based evidence is going to align so comfortably with the evidentiary needs of policy makers, psychiatrists or psychologists (and once we move to consider the psy-professions, we are already one degree removed from influencing policy processes). So, in order for psychological evidence to be utilised by community stakeholders, it may have to risk being 'sidelined' in other forums. This question is as much ethical as scientific and will confront psychologists trying to influence policy with the challenging question, what are the implications of this evidence not for policy but for the communities many of us are paid to serve? As we have argued in this paper, this question is less straightforward than we might like to think.

Received: 30 April 2018 Accepted: 3 August 2018

Published online: 28 August 2018

\section{References}

Ali S, Rhodes L, Moreea O, McMillan D, Gilbody S, Leach C, Lucock M, Lutz W, Delgadillo J (2017) How durable is the effect of low intensity CBT for depression and anxiety? Remission rates and relapse in a longitudinal cohort study. Behav Res Ther 94:1-8
BPS (2014) Understanding psychosis and schizophrenia. https://www1.bps.org.uk/ system/files/Public\%20files/rep03_understanding_psychosis.pdf Accessed 24 Mar 2018

Cairney P (2016) The politics of evidence-based policy making. Palgrave, London

Cairney P (2018) The UK government's imaginative use of evidence to make policy. Br Polit https://doi.org/10.1057/s41293-017-0068-2

Cancian M, Slack K, Yang MY (2010) The effect of family income on risk of child maltreatment. Institute for research on poverty: Discussion paper no. 1385-10. http://www.irp.wisc.edu

Clark DM (2011) Implementing NICE guidelines for the psychological treatment of depression and anxiety disorders: The IAPT experience. Int Rev Psychiatry 23(4):318-327. https://doi.org/10.3109/09540261.2011.606803

Delgadillo J, Asaria M, Ali S, Gilbody S (2015) On poverty, politics and psychology: the socioeconomic gradient of mental healthcare utilisation and outcomes. $\mathrm{Br}$ J Psychiatry 1-2 https://doi.org/10.1192/bjp.bp.115.171017

Davies W (2015) The happiness industry: how the government and big business sold us wellbeing. Verso, UK

Farsides T, Sparks P (2015) Buried in bullshit. Psychologist 29(5):368

Fishbeyn B (2015) When ideology trumps evidence: a case for evidence based health policies. Am J Bioeth 15(3):1-2

McInnes B (2014) The researcher, and so, again, to IAPT. Therapy Today 25 (10): $18-24$

NHS Digital (2016) Psychological therapies: Annual report on the use of IPAT services. Health and Social Care Information Centre

NHS Digital (2017) Improving access to psychological therapies (IAPT): Executive Summary December 2017. Health and Social Care Information Centre

New York Times (2017) England's Mental Health Experiment: No-Cost Talk Therapy. https://www.nytimes.com/2017/07/24/health/england-mentalhealth-treatment-therapy.html Accessed 24 Mar 2018

Perkins A (2015) The Welfare Trait- How state benefits affect personality. Palgrave Macmillan.

Prinja S (2010) Role of ideas and ideologies in evidence-based health policy. Iran J Publ Health 39(1):64-69

Rhodes R (2015) Replication- latest twists. Psychologist 29(5):334

Speed E, Taggart D (2012) It's your problem but you need us to help you fix it: the paradox at the heart of the IAPT agenda. Asylum Mag Democr Psychiatry 19 (3):23-24

Tonge WL, James DS, Hillam SM (1975) Families without hope: a controlled study of 33 problem families. Ashford, Headley

Watts J (2016) IAPT and the ideal image in The future of psychological therapy: from managed care to transformational practice. In: John Lees (Ed.), Routledge, UK

\section{Additional information}

Competing interests: The authors declare no competing interests.

Reprints and permission information is available online at http://www.nature.com/ reprints

Publisher's note: Springer Nature remains neutral with regard to jurisdictional claims in published maps and institutional affiliations.

Open Access This article is licensed under a Creative Commons Attribution 4.0 International License, which permits use, sharing, adaptation, distribution and reproduction in any medium or format, as long as you give appropriate credit to the original author(s) and the source, provide a link to the Creative Commons license, and indicate if changes were made. The images or other third party material in this article are included in the article's Creative Commons license, unless indicated otherwise in a credit line to the material. If material is not included in the article's Creative Commons license and your intended use is not permitted by statutory regulation or exceeds the permitted use, you will need to obtain permission directly from the copyright holder. To view a copy of this license, visit http://creativecommons.org/ licenses/by/4.0/

(c) The Author(s) 2018 